\title{
HARDY'S INEQUALITY AND THE LITTLEWOOD CONJECTURE
}

BY O. CARRUTH McGEHEE, LOUIS PIGNO AND BRENT SMITH

Let $\mathbf{T}$ be the circle group, $\mathbf{Z}$ the additive group of integers, $\mathbf{C}$ the complex numbers and $M(\mathrm{~T})$ the customary convolution algebra of Borel measures on $\mathbf{T}$; for $\mu \in M(\mathrm{~T})$ and $n \in \mathbf{Z}$

$$
\hat{\mu}(n)=\int_{\mathbf{T}} e^{-i n \theta} d \mu(\theta)
$$

If $\mu \in M(\mathrm{~T})$ and $\hat{\mu}(n)=0$ for all $n<0$, we say $\mu$ is of analytic type; Hardy's inequality $[4$, p. 70$]$ states that for all measures $\mu$ of analytic type

$$
\sum_{1}^{\infty} \frac{|\hat{\mu}(k)|}{k} \leqslant \pi\|\mu\| .
$$

The purpose of this note is to announce the following generalization of Hardy's inequality:

THEOREM. There is a real number $C>0$ such that given any $F=\left\{n_{1}<\right.$ $\left.n_{2}<\cdots<n_{N}\right\} \subset \mathrm{Z}$ and $a_{j} \in \mathbf{C},\left|a_{j}\right|=1(j=1,2, \ldots, N)$, there corresponds $a$ trigonometric polynomial $t$ on $\mathrm{T}$ satisfying

(i) $\|t\|_{\infty} \leqslant 1$;

(ii) $\left|\hat{t}\left(n_{j}\right)\right| \geqslant C / j(j=1,2, \ldots, N)$;

(iii) $\left|\operatorname{sgn} \hat{t}\left(n_{j}\right)-a_{j}\right|<2 / 5(j=1,2, \ldots, N)$.

A simple convolution product argument now establishes the Littlewood conjecture [3] on the $L^{1}$ norm of exponential sums.

COROLlaRY. If $p(\theta)=\Sigma_{k=1}^{N} c_{k} e^{i n_{k} \theta}$ where $\left\{n_{1}<n_{2}<\cdots<n_{N}\right\} \subset \mathbf{Z}$ and $\left|c_{k}\right| \geqslant 1(k=1,2, \ldots, N)$, then

$$
\|p\|_{1} \geqslant \frac{3 C}{5} \log N
$$

Our proofs are based on some arguments in [5] which were inspired by the fundamental work of P. Cohen [1] and J. Fournier [2] ; detailed proofs will appear in [6].

Received by the editors February 12, 1981.

1980 Mathematics Subject Classification. Primary 42 A05.

(C) 1981 American Mathematical Society $0002-9904 / 81 / 0000-0306 / \$ 01.50$ 


\section{REFERENCES}

1. P. J. Cohen, On a conjecture of Littlewood and idempotent measures, Amer. J. Math. 82 (1960), 191-212.

2. J. J. F. Fournier, On a theorem of Paley and the Littlewood conjecture, Ark. Mat. 17 (1979), 199-216.

3. G. H. Hardy and J. E. Littlewood, $A$ new proof of a theorem on rearrangements, J. London Math. Soc. 23 (1948), 163-168.

4. K. Hoffman, Banach spaces of analytic functions, Prentice-Hall, Englewood Cliff, N. J., 1962.

5. L. Pigno and B. Smith, Quantitative behaviour of the norms of an analytic measure (submitted).

6. O. C. McGehee, L. Pigno and B. Smith, Hardy's inequality and the $L^{1}$ norm of exponential sums Ann of Math. (to appear).

DEPARTMENT OF MATHEMATICS, LOUISIANA STATE UNIVERSITY, BATON ROUGE, LOUISIANA 70803

DEPARTMENT OF MATHEMATICS, KANSAS STATE UNIVERSITY, MANHATTAN, KANSAS 66506

DEPARTMENT OF MATHEMATICS, ILLINOIS STATE UNIVERSITY, NORMAL, ILLINOIS 61761 